\title{
Emerging Strategies for Failed Percutaneous Transluminal Coronary Angioplasty
}

\author{
Eric J. Topol, MD
}

$\mathrm{S}$ econd only to the problem of restenosis, abrupt closure during percutaneous transluminal coronary angioplasty (PTCA) represents a significant procedural complication. Of the 200,000 PTCA procedures performed in the United States in 1987, abrupt closure occurred in approximately 10,000 patients-resulting in triage to emergency coronary artery bypass surgery in $>6,000$ patients and $>1,000$ deaths. ${ }^{1-3}$

Current approaches to this problem have been limited. After intracoronary nitroglycerin is given, intracoronary or intravenous thrombolytic therapy has been used in some cases. However, spasm or thrombosis is very rarely the principal cause of abrupt closure. Typically, the inciting event is a complex intimal tear. Definite establishment of the etiology is confounded by the lack of adequate angiographic distinction between thrombus and dissection; our methods for dccision-making under these circumstances are relatively crude. A standard approach, which has evolved empirically to "tack up" the tear, is the use of prolonged inflations ( 2 to 5 minutes), with a larger balloon dilatation catheter $(0.5-\mathrm{mm}$ size increase) at low pressure ( 3 to 5 atmospheres). ${ }^{4}$ The direct intracoronary administration of propranolol or fluorinated hydrocarbons has increased our capacity to prolong inflations by virtue of a decelerated induction of myocardial ischemia. ${ }^{5,6}$ Combined with these various pharmacologic interventions, this overall "tack up" strategy appears to represent the best current approach to the management of abrupt closure.

In the late 1970s, when a decision was made to send the patient for emergency coronary bypass surgery, the earliest, most readily available "bail out" strategy was to leave or reintroduce the guidewire across the narrowing. ${ }^{7}$ In 1985 , Hinohara et al $^{8}$ introduced the autoperfusion catheter, a $3.5 \mathrm{Fr}$ catheter with 36 sideholes, through which passive aortocoronary blood flow can be achieved if positioned across the lesion and if adequate systemic blood pressure is present. This catheter may serve as a "bridge" to the operating room and has clearly proved helpful, allowing stabilization of some patients and internal mammary artery graft implantation..$^{8,9}$ However, use of the autoperfusion catheter can be problematic for several reasons: (1) it may not be possible to recross the zone of occlusion with a wire, thereby not permitting its introduction; (2) in situations with a

From the Division of Cardiology, Department of Internal Medicine, University of Michigan Medical Center, Ann Arbor, Michigan. Manuscript received September 12, 1988; revised manuscript received September 20, 1988, and accepted September 22.

Address for reprints: Eric J. Topol, MD, Division of Cardiology, University of Michigan Medical Center, B1 F245, 1500 East Medical Center Drive, Ann Arbor, Michigan 48109-0022. guidewire secured across the narrowing, in a target vessel with tortuosity or excessive angulation, it may not be possible to pass the catheter distally; (3) adequate systolic blood pressure (>80 $\mathrm{mm} \mathrm{Hg}$ ) is required; and (4) the catheter is predisposed to thrombotic occlusion, owing to relative stagnation of flow and the likelihood of preexisting intraluminal fibrin at the time of insertion. Thus, the current state of the art of failed coronary angioplasty management can be summarized as the use of empiric strategies that have limited effectiveness for sustaining target vessel patency, frequently resulting in emergency backup surgical revascularization.

Quite recently, several innovative methods have been developed and preliminary clinical evaluation of most of these is currently underway. Although many of these methods were originally designed to address restenosis, therc is more imminent potential for some to deal with abrupt closure. These new approaches can be categorized as either direct or indirect coronary artery methods.

Of the direct approaches, the autoperfusion dilatation catheter ${ }^{10}$ is similar to the bail out catheter but the balloon allows very prolonged inflation, which anecdotally has reduced the need for emergency bypass surgery. The endoluminal stent, ${ }^{11,12}$ which has also been developed to reduce restenosis, may find its place in the establishment of sustained patency after abrupt closure. To date, Sigwart has deployed a stent in 19 cases of "refractory" closure, withoul incident or need for bypass surgery (Ulrich Sigwart, personal communication). Laser "welding" of the dissected intimal segment represents another alternative that has proved useful in experimental studies and has just begun clinical testing for abrupt closure. ${ }^{13,14}$ It is likely that other forms of "pyroplasty" such as electrical or radiofrequency energy sources may be equally effective for this purpose. Recently, the Simpson atherectomy device has been used to excise intimal flaps and it too has potential as a direct intervention in this setting.

Besides intraaortic balloon counterpulsation, which has frequently been used for intractable abrupt closure, 2 new indirect percutaneous interventions are being assessed. The back door perfusion approach is the coronary sinus, and 2 different methods-synchronized retroperfusion or intermittent balloon occlusion-have been tested. ${ }^{15,16}$ It has not yet been established whether coronary sinus interventions will restore adequate myocardial perfusion in patients. A promising indirect intervention is percutaneous femoral-femoral cardiopulmonary bypass. If this can be quickly and reliably initiated, systemic perfusion is ensured and marked unloading of the left ventricle leads to a very low myocardial oxygen 
consumption. ${ }^{17}$ Although this technique requires surgical femoral vascular repair at the completion of the procedure, and $35,000 \mathrm{U}$ of heparin, it is already being used prophylactically in more than 30 catheterization laboratories in the US (C.R. Bard, Inc., personal communication). This explosive application of percutaneous cardiopulmonary bypass, known as "supported angioplasty", will be the subject of many presentations at next year's national meetings.

These new techniques, however, may engender new problems. First, the "high risk" patient will remain at high risk no matter what new strategy is selected. It will therefore be difficult to objectively evaluate the true benefit of a particular technique and randomization to a control arm is not likely to be feasible in a trial. Second, centers without in-house cardiac surgical resources will increasingly consider the use of one or more of these techniques as a license to practice coronary angioplasty. It is necessary to emphasize that none of the stratcgies under development is likely to obviate the absolute requirement for backup, emergency surgical revascularization. ${ }^{18}$ Third, with an array of possible mechanical and pharmacologic approaches, a more tailored and precise scheme will be necessary. The parallel development of flexible coronary angioscopy, providing direct visualization of the diseased segment, is important and may make this possible. Without question, concern and management of abrupt closure after PTCA have plagued patients and operators for many years. With the many new and exciting strategies currently under development, there is a realistic opportunity to markedly improve this procedure.

\section{REFERENCES}

1. Detre K, Holubkov R, Kelsey S, Cowley M, Kent K, Williams D, Myler R, Faxon D, Holmes D Jr, Bourassa M, Block P, Gosselin A, Bentivoglio L, Leatherman L, Dorros G, King S III, Galichia J, Al-Bassam M, Leon M, Robertson T, Passamani E. Percutaneous transluminal coronary angioplasty in 1985-1986 and
1977-1981. N Engl J Med 1988;318:265-270.

2. Hospital Statistics. Washington, DC: American Hospital Association, 1987 3. Chokshi SK, Meyers S, Abi-Mansour P. Percutaneous transluminal coronary angioplasty: ten years' experience. Prog Cardiovasc Dis 1987;30:147-210.

4. Stack RS. Technical aspects of emergency percutaneous transluminal coronary angioplasty. In: Topol EJ, ed. Acute Coronary Intervention. New York: Alan R. Liss, 1988:61-78.

5. Cleman M, Jaffee CC, Wohlgelernter D. Prevention of ischemia during percutaneous transluminal coronary angioplasty by transcatheter infusion of nxygenated Fluosol DA 20\%. Circulation 1986;74:555-562.

6. Zalewski A, Goldberg S, Dervan JP, Siysh S, Kusiak V, Maroko PR. Myocardial protection during coronary occlusion in man: beneficial effects of regional $\beta$ blockade (abstr). JACC 1985;5:445

7. Hollman J, Gruentzig AR, Douglas JS Jr, King SB III, Ischinger T, Meier B. Acute occlusion after percutaneous transluminal coronary angioplasty - a new approach. Circulation 1983;68:725-732.

8. Hinohara T, Simpson JB, Phillips HR, Stack RS. Transluminal intracoronary reperfusion catheter: a device to maintain coronary reperfusion between failed coronary angioplasty and emergency coronary bypass surgery. $J A C C$ 1988;11: 977-982.

9. Kereiakes DJ, Abbottsmith CW, Callard GM, Flege JB Jr. Emergent internal mammary artery grafting following failed percutaneous transluminal coronary angioplasty: use of transluminal catheter reperfusion. Am Heart $J$ 1987; 113:1018-1020.

10. Turi ZG, Campbell CA, Gottimukkala MV, Kloner RA. Preservation of distal coronary perfusion during prolonged balloon inflation with an autoperfusion angioplasty catheter. Circulation 1987;75:1273-1280.

11. Sigwart U, Puel J, Mirkovitch V, Joffre F, Kappenberger L. Intravascular stents to prevent occlusion and restenosis after transluminal angioplasty. $N$ Engl J Med 1987;316:701-706

12. Schatz RA, Palmaz JC, Tio FO, Garcia F, Garcia O, Reuter SR. Balloonexpandable intracoronary stents in the adult dog. Circulation 1987;76:450-457 13. Sanborn TA, Haudenschild CC, Garber GR, Ryan TJ, Faxon DP. Angiographic and histologic consequences of laser thermal angioplasty: comparison with balloon angioplasty. Circulation 1987,75:1281-1286.

14. Spears JR. Percutaneous transluminal coronary angioplasty restenosis: potential prevention with laser balloon angioplasty. Am J Cardiol 1987,60:61B $64 B$.

15. Faxon DP, Jacobs AK: Coronary sinus retroperfusion and intermittent occlusion. In: Topol EJ, ed. Acute Coronary Intervention. New York: Alan R. Liss, 1988:255-270.

16. Gorc JM, Wciner BH, Benotti JR, Sloan KM, Okike ON, Cuenoud HF, Gaca JM, Alpert JS, Dalen JE. Preliminary experience with synchronized coronary sinus retroperfusion in humans. Circulation 1986;74:381-388.

17. Kanter KR, Pennington DG, Vandormael M, Kern MJ, McBride LR, Naunheim KS, Braun P, Taub J, Willman VL. Emergency resuscitation with extracorporeal membrane oxygenation for failed angioplasty. $J A C C$ 1988:11:149 A.

18. ACC/AHA Task Force Report. Guidelines for percutaneous transluminal coronary angioplasty: a report of the American College of Cardiology/American Heart Association Task Force on Assessment of Diagnostic and Therapeutic Cardiovascular Procedures (Subcommittee on Percutaneous Transluminal Coronary Angioplasty). JACC 1988,12:529-545. 